\title{
OS MORLOCKS NA PERSPECTIVA DE OPRIMIDOS E OS DIÁLOGOS COM A PEDAGOGIA DE PAULO FREIRE
}

\author{
Cintia C. Maciel Neves* \\ Gelson Weschenfelder ${ }^{* *}$ \\ HildegardSusana Jung ${ }^{* * *}$
}

\begin{abstract}
RESUMO: Esse texto visa relacionar o retrato de opressão presente em Massacre de Mutantes (Marvel, 1986) com os estudos de Paulo Freire. Comparando o comportamento dos mutantes conhecidos como Morlocks, conseguimos relacioná-los aos oprimidos da obra de Freire. A análise encontrou aproximações entre as obras citadas, pois os X-Men da obra de Freire são os que, por não compartilharem da mesma cultura, ou da mesma situação econômico-educacional, acabam sendo excluídos e oprimidos. Concluímos que nos completamos, aprendemos e crescemos, na diversidade, o que podemos alcançar por meio do diálogo, da problematização e da escuta.
\end{abstract}

Palavras-Chave: Morlock; X-Men; Paulo Freire; Opressão; Educação.

\section{THE MORLOCKS FROM THE PERSPECTIVE OF THE OPPRESSED AND THE DIALOGUES WITH PAULO FREIRE}

\begin{abstract}
This text aims to relate the portrait of oppression present in Mutant Massacre with Paulo Freire's studies. Comparing the behavior of the mutants known as Morlocks we can relate them to the oppressed in Freire's work. The analysis found similarities between the cited works, since the X Men of Freire's work are those who, because they do not share the same culture, or the same economic-educational situation, end up being excluded and oppressed. We conclude that we complete ourselves, learn and grow, in diversity, which we can achieve through dialogue, problematization and listening.
\end{abstract}

Keywords: Morlock; X-Men; Freire; OpPression; Education.

\footnotetext{
*Discente do curso de Pedagogia na Universidade La Salle. E-mail: cintianmaciel@gmail.com Orcid: 0000-0003-0838-5972

* * Pós doc no PPG em Processos e Manifestações Culturais, na Universidade Feevale. Doutor/Mestre em Educação. Email: gellfilo@gmail.com_Orcid: 0000-0002-6571-8027

*** Coordenadora do Curso de Pedagogia na Universidade La Salle, Doutora em Educação pela Universidade LaSalle. Email: hildegard.jung@unilasalle.edu.br Orcid: 0000-0001-5871-3060.
} 


\section{Introdução}

No início da década de 1960, a Marvel Comics já havia revolucionado o modo de apresentar o gênero de superaventura nos quadrinhos: super-heróis como Homem-Aranha e Hulk estavam entre as Histórias em Quadrinhos (HQs) mais vendidas no mercado. Stan Lee e Jack Kirby transformaram o universo Comics em 1963, criando super-heróis que já nasciam com superpoderes, devido a mutações genéticas. X-Men é o melhor exemplo desse tipo de super-heróis.

A tese central que sustenta esses super-heróis é a de que a "mutação é a chave da nossa evolução. Ela permite-nos evoluir a partir de um organismo celular até à espécie dominante do planeta, num processo lento que costuma levar milhares e milhares de anos. Mas a cada poucas centenas de milênios a evolução dá um salto” (Singer, 2000).

Sabemos que dificilmente os filhos do átomo terão um "final feliz", pois seja em Massacre de Mutantes ou nos arcos que seguem, a história sempre termina com algumas perdas e o aumento da população anti-mutantes. O arco Massacre de Mutantes, que teve início em 1986, com a HQ intitulada $A$ manhã seguinte e terminou em 1987, com a HQ intitulada Psylocke, trata do ataque dos Carrascos ${ }^{1}$. Os vilões atacam os subterrâneos, matando vários Morlocks e, em seguida, entram em batalha com os X-Men e ambos acabam sofrendo perdas, aliás, as perdas são um ponto importante dessa saga, pois além dos ferimentos físicos, as feridas emocionais dos mutantes são retratadas nesse momento. Tempestade, que havia conquistado a liderança dos Morlocks após uma batalha com Callisto, mostra-se profundamente abalada, questionando sua própria capacidade como líder e heroína, cogitando a possibilidade de abandonar tudo. Posteriormente, em outra luta com Callisto, Tempestade ouve da ex-líder dos Morlocks que seu lugar é na liderança. Outra equipe, além dos X-Men, que também se faz presente no arco do Massacre é o X-Factor ${ }^{2}$ (publicado no Brasil com o nome de Fator X), que segue uma pista deixada por uma criança mutante e conseguem salvar muitos da espécie em perigo.

O mutante Anjo, que havia sido sequestrado por Callisto com a intenção de fazê-lo seu companheiro, tenta salvar os Morlocks, mas é emboscado pelos Carrascos e acaba com grandes ferimentos em suas asas. Levado até um hospital, suas asas são amputadas e isso o deixa profundamente abalado, mais tarde acaba cometendo suicídio. Descobre-se posteriormente que o amputamento de suas asas foi planejado pelo diretor do X-Factor, Cameron Hodge, que queria tomar posse da fortuna de Warren e planejou também a queda do X-Factor, ainda se sabe que Warren não morreu em sua tentativa de suícido, foi sequestrado e alterado geneticamente por Apocalipse e tornou um de seus cavaleiros, conhecido como Arcanjo.

\footnotetext{
${ }^{1}$ Uma equipe formada por Caçador de Escalpos, Arco Voltaico, Maré Selvagem, Vertigo, Embaralhador, Arpão, Arrasta Quarteirão, Prisma, Maligna e Dentes de Sabre.

${ }^{2}$ Formado pelos X-Men originais: Ciclope, Homem de Gelo, Fera, Garota Marvel e Anjo.
} 
Para além dos ferimentos, os ataques dessa saga marcam um ponto crucial na cronologia dos filhos do átomo. A partir deste ponto, vários mutantes decidem seguir rumos diferentes. Kitty Pride junto com Noturno parte rumo à Inglaterra para que se curem completamente. Lá acabam conhecendo Brian Braddock, sua namorada Meggan e sua irmã Psylocke e fundam o grupo que fica conhecido Excalibur.

Os X-Men restantes ficam em busca de respostas para os ataques dos Carrascos, mais tarde descobrem sobre o Senhor Sinistro e o confrontam em uma batalha final, na qual a Mansão X é completamente destruída. Além disso, após o Massacre o X-Factor precisa enfrentar o vilão Apocalipse para libertar Warren de seu domínio.

Outro ponto importante na história é o fato de que em nenhum momento X-Men e X-Factor se encontram, já que os integrantes do X-Factor se disfarçaram e se apresentaram como caçadores de mutantes e assim os X-Men realmente acreditaram que a outra equipe era formada por caçadores. O encontro das duas equipes se dá na saga Inferno (outubro 1988 - agosto 1989), quando é revelado a Scott Summers a verdade sobre a esposa que abandonou para ajudar os mutantes durante o massacre, Madelyne Pryor, que era um clone de Jean Grey criada pelo Senhor Sinistro.

Refletindo sobre a história do ponto de vista da opressão, poderia ser encontrada uma relação com a ideia de opressão abordada nas obras de Paulo Freire? Segundo o autor, a opressão acomoda os oprimidos em sua própria engrenagem, faz com que temam a sua liberdade, que tenham medo de buscála ou assumi-la. Para Freire, o oprimido está preso no determinismo, as coisas são assim por que tem de ser, aqueles que estão "imersos na própria engrenagem da estrutura dominadora, temem a liberdade, enquanto não se sentem capazes de correr o risco de assumi-la" (FREIRE, 2005, p. 38). Neste cenário, o objetivo dessa pesquisa, além de analisar os discursos presentes nas HQ’S de X-Men e nos livros de Freire, é relacionar os diálogos presentes em Massacre de Mutantes com as obras do educador Paulo Freire.

\section{As histórias em quadrinhos em ambiente escolar}

A grande maioria das pessoas restringem as histórias em quadrinhos de super-heróis ao entretenimento do grande público, principalmente do público infanto-juvenil. Analisando a proposta educacional de Freire, podemos perceber que ela propõe que o conhecimento que o educando traz consigo seja articulado em sala. Toda construção do saber parte da vivência do educando. Dessa forma, levamos em consideração que, no espaço escolar, sempre existirá alguém que aprendeu a ler utilizando histórias em quadrinhos, ou então que refletiu sobre sua vida em algum momento, ao ler histórias em quadrinhos, são inúmeras possibilidades.

Porém, poucos profissionais da educação acreditam que os personagens podem ser usados como recurso pedagógico de motivação e inspiração no desenvolvimento de crianças, apesar de essa inserção ser vista com grande animação por parte dos educandos. "As histórias em quadrinhos aumentam a 
motivação dos estudantes para o conteúdo das aulas, aguçando sua curiosidade e desafiando o senso crítico”. (RAMA; VERGUEIRO, 2006, p. 21) Com esta simples movimentação do mundo simbólico infanto-juvenil, algumas crianças revelaram sentir-se especialmente empoderadas, seguras, confiantes e com a coragem e o olhar esperançoso de um super-herói (HARRIS, 2016).

Um estudante que confia em suas potencialidades e tem autonomia para dialogar, dizer suas palavras, é um estudante que, de fato, refletirá o mundo e terá a criticidade necessário para mudá-lo. Fiori (2005) coloca nesse ponto o próprio sentido da educação: aprender a escrever sua vida, como autor e como testemunha de sua história, isto é, biografar-se, existenciar-se, historicizar-se.

Buscando referências em documentos legais da educação, encontramos embasamento para a inserção das histórias em quadrinhos em ambiente escolar. Dentre as competências presentes na Base Nacional Comum Curricular do $1^{\circ}$ ao $5^{\circ}$ ano estão: identificar o efeito de sentido produzido pelo uso de recursos expressivos gráfico-visuais em textos multissemióticos; construir o sentido de histórias em quadrinhos e tirinhas, relacionando imagens e palavras e interpretando recursos gráficos; reconhecer o conflito gerador de uma narrativa ficcional e sua resolução, além de palavras, expressões e frases que caracterizam personagens e ambientes; Analisar a validade e força de argumentos em argumentações sobre produtos de mídia (filmes, desenhos animados, HQs, games etc.), com base em conhecimentos sobre os mesmos. (BNCC, 2017) Encontramos também nos Parâmetros Curriculares Nacionais referência ao "acesso de todos à totalidade dos recursos culturais relevantes para a intervenção e a participação responsável na vida social” (PCN’s,1997, p. 27). Ainda segundo os PCN's:

Materiais de uso social frequente são ótimos recursos de trabalho, pois os alunos aprendem sobre algo que tem função social real e se mantêm atualizados sobre o que acontece no mundo, estabelecendo o vínculo necessário entre o que é aprendido na escola e o conhecimento extraescolar. A utilização de materiais diversificados (...) faz o aluno sentir-se inserido no mundo à sua volta (1997, p. 67).

Desta maneira, com um bom planejamento e um bom embasamento teórico é possível inserir histórias que já fazem parte da imaginação e da vivência de cada estudante em sala de aula. Além do uso como ferramenta pedagógica, as HQs podem auxiliar no processo de construção da identidade pessoal de casa estudante, como aponta Weschenfelder (2014), quando pontua que os super-heróis são modelos de valores de ética e educação moral, uma vez que apresentam potencial como recursos educativos e podem se fazer presentes nas salas de aula.

Nesse sentido, lançamos o olhar as histórias vividas pelos X-Men, mais especificamente pelo grupo de mutantes conhecidos como Morlocks associados ao discurso de Freire. Propondo em sala de aula a reflexão sobre os espaços ocupados por cada um. Somos todos atuantes na sociedade e a educação não pode tomar caráter neutro e permitir que sejam formados sujeitos-objetos na história do mundo em que vivem. Para Freire (2015, p. 137), “a postura crítica e desperta nos momentos necessários não pode faltar” sendo assim, a educação se faz pela conscientização.

Propiciando vivências e reflexões, onde educandos tomem consciência de si e do mundo, 
estaremos de fato praticando a pedagogia freiriana que acredita que educar é intervir no mundo. A reflexão que buscamos é: Quem são os Morlocks? Onde eles estão? Por qual motivos estão lá? O que vem constantemente acontecendo a eles, história após história, é justo? Quem são os Morlocks na nossa sociedade? O que vem acontecendo aos que convivem conosco tem sido justo? Eles têm consciência de seu lugar no mundo? Algum de nós está ocupando essa posição? Estamos refletindo e tentando intervir ou seguimos nos beneficiando dessa inconsciência?

\section{O universo X-Men}

Nas HQs dos X-men, há humanos em várias partes do mundo que nasceram com modificações genéticas. Humanos que, como resultado de um súbito salto evolucionista, nasceram com habilidades super-humanas latentes. Há seres que podem manipular o clima, o gelo e até mesmo mentes humanas, outros podem atravessar paredes ou voar. Existem muitos com aparências atípicas. Tais mutações resultam da evolução provocada pelo "fator X" que está no código genético desses seres humanos modificados. Em linguagem científica, esse seria o novo degrau da evolução humana: a evolução de homo sapiens a homo superior (REBLIN, 2008, p. 83). Logo, por se tratar de seres diferentes de qualquer cidadão comum, muitos os consideram uma ameaça à própria sociedade humana. Devido às capacidades incomuns, tais mutantes causam medo e insegurança nos seres humanos não evoluídos.

Seres humanos diferentes foram obrigados a aprender a conviver (ou não), que conduz à questão da alteridade. [...] A reflexão acerca do outro, sempre ocorre no encontro com o outro diferente e, nesse encontro, a alteridade sempre oscilava entre uma visão depreciativa e uma visão ingênua acerca do outro diferente. [...] Mas ambas as visões desconsideravam o outro como ser humano (REBLIN, 2008, p. 83-84).

Os Morlocks são, originalmente, personagens de H. G. Wells (1981), saídos do livro "A Máquina do Tempo", são humanóides que vivem no subterrâneo. Eles descendem dos seres humanos que se esconderam de uma guerra nuclear no subsolo e, durante a evolução desses humanos, surgiu essa nova espécie, são muito pálidos devido à falta do sol e, sendo assim, são extremamente sensíveis à luz (1981, p. 307).

Eles ficaram tão populares que outros autores os utilizaram em seus livros, como por exemplo, Egon Friedell em Die Reise mit der Zeitmaschine (1946) e The Man Who Loved Morlocks (1981), de David Lake.

Em uma clara referência aos Morlocks de H. G. Wells (1981), a equipe criativa da Marvel Comics em 1983 incluiu-os em Uncanny X-men \#169 como personagens mutantes que se escondem nos esgotos. Esse grupo sente-se inferior aos demais mutantes, devido à sua aparência física. Já foram pacíficos, mas como sempre estiveram tentando ganhar algo do mundo exterior e não obtiveram sucesso algum, acabaram se tornando agressivos.

Os X-Men sempre souberam da existência dos Morlocks nos subterrâneos, mas jamais fizeram contato, até que na HQ \#169 os carrascos do Senhor Sinistro invadem o subterrâneo e começam a 
assassiná-los. A maioria dos Morlocks foi assassinada em Massacre de Mutantes, os poucos que restaram se juntaram ao Nação Gene em um universo paralelo.

\section{A pedagogia de Paulo Freire}

Falar sobre Paulo Freire é, sem dúvida, falar sobre a crença que ele possuía nos homens, pois esta é a linha que conduz toda sua prática. De acordo com Araújo Freire (2017), ele acreditava que uma educação problematizadora e crítica seria o apoio para a libertação dos oprimidos. Ainda segundo ela, os núcleos temáticos de Freire sempre andam por entre as condições de opressão e classe social. Assim, as obras de Freire preocupam-se em tratar da opressão e da exclusão. Para Araújo Freire (2017):

Como todas essas questões sobre as quais se debruçou ainda permanecem no mundo, a atualidade e a relevância do pensamento de Paulo são um fato inconteste ainda neste século XXI que se inicia, mesmo que alguns pensadores conservadores pós-modernos reacionários queiram negar isso. $\mathrm{O}$ problema da libertação dos oprimidos e das oprimidas está plenamente vigente, principalmente depois da arrancada neoliberal e da globalização da economia. A prepotência desses pensadores a serviço dos "donos do mundo", que querem padronizar e massificar todos os povos dos diferentes continentes, aniquilando culturas milenares e arrancando com "guerras preventivas" as riquezas alheias, prevalecendo-se das tecnologias mais avançadas, vem produzindo o terrorismo com sua também violência generalizada (ARAÚJO FREIRE, 2017, p. 467).

Em sua célebre obra Pedagogia do Oprimido, Freire (2005) analisa o oprimido e o opressor, coloca sobre as questões que os aproximam e os fazem existir. Questiona a educação bancária - aquela que 'corta' as curiosidades e potencialidades do aluno - e exemplifica a educação libertadora, pela qual o oprimido consegue transformar a si e a seu opressor e assim, mudar o contexto no qual se insere.

\section{A representação dos oprimidos em Massacre de Mutantes}

Um conceito que é necessário apresentar é o de oprimido e opressor segundo Freire (2005): oprimido e opressor são classes em oposição e em luta, mas a relação de opressão também, em algumas vezes, pode partir de oprimido para oprimido. Dizia Freire (2005):

Raros são os camponeses que, ao serem 'promovidos' a capatazes, não se tornam mais duros opressores de seus antigos companheiros do que o patrão mesmo. Poder-se-a dizer - e com razão- que isto se deve ao fato de que a situação concreta, vigente, de opressão não foi transformada (FREIRE, 2005, p. 36).

A relação entre oprimido-opressor também é pautada na ausência de ser integralmente humanos, "a desumanização, que não se verifica apenas nos que têm sua humanidade roubada, mas também, ainda que de forma diferente, nos que a roubam" (FREIRE, 2005, p. 32). No entanto, oprimidos e opressores não estão determinados a ocupar essas posições para sempre, a obra de Freire deixa claro que se as 
posições estivessem determinadas pois assim tem de ser não haveria por que falar em libertação. É necessário lembrar também da insistência de Freire em falar da libertação e não da caridade. Olhando para Massacre de Mutantes, se faz necessário que a equipe dos X-Men se reconheça na posição do opressor, uma vez que, por anos, silenciaram-se quanto à violência sofrida pelos Morlocks e reconhecendo-se na posição de opressores, consigam entrar na luta para mudar a situação e não se compadeçam pela situação precária em que seus companheiros vivem. Nessa perspectiva, para Freire (2005) a briga necessária seria para que a justiça social se implantasse antes da caridade.

É necessário pontuar que a aparência da maioria dos integrantes do X-Men em nada mudava, se assemelhavam a qualquer outro humano e ainda assim, a convivência entre mutantes e humanos nunca se deu de forma pacífica. Já os Morlocks se sentiam marginalizados quanto aos demais mutantes e viviam nos esgotos. Nessa perspectiva, podemos dizer que os Morlocks haviam aceitado que jamais seriam dignos de conviver em sociedade, perderam a vontade de lutar.

Em Pedagogia da autonomia (2015), Freire menciona que não se deve silenciar em face do discurso da impossibilidade da mudança porque a realidade é assim. E o que podemos perceber, analisando criticamente as aparições dos Morlocks é justamente isso: a aceitação de fatos impostos a eles, seguindo o pensamento freiriano, podemos afirmar que esse grupo perdeu a consciência crítica de seu papel, que não intervém no mundo, não diz sua palavra. Segundo Freire (2000, p. 114), "seria uma agressiva contradição se, inacabado e consciente de seu inacabamento, o ser humano não se inserisse num permanente processo de esperançosa busca". Tomamos por essa busca, a busca de todos os outros mutantes que, conscientes de suas diferenças, buscam seu espaço, mas esse grupo isolado, mesmo consciente de sua diferença, não busca seu espaço, não se insere nessa esperançosa procura dos demais mutantes pelo dia em que viverão em harmonia na sociedade humana.

Na perspectiva freiriana, "Se fôssemos determinados, não importa por quê, pela raça, pela cultura, pela classe, pelo gênero, não tínhamos como falar em liberdade, decisão, ética, responsabilidade. Não seríamos educáveis, mas adestráveis” (FREIRE, 2000, p. 121).

Freire valida o tempo todo em suas obras o sentimento do oprimido. O que observamos em Massacre de Mutantes são sentimentos de inferioridade e raiva por parte dos Morlocks. Em discussão com a personagem Tempestade, Callisto afirma:

Mutantes, sim, mas não como vocês. Somos fugitivos, párias... Pessoas sem lar, sem família, odiados e caçados pelos poderes que não queremos ou entendemos. Deformados, desprezados, abandonados. O 'beco' é um abrigo antibombas construído secretamente durante a guerra fria. Quando foi abandonado, eu o encontrei, fiz dele o meu lar, e depois fiz de santuário para aqueles como eu (CLAREMONT, 1986, p. 10).

Mais uma vez, podemos voltar ao conformismo do qual Freire (2000 p. 78) fala: "Que fazer? A realidade é assim mesmo, seria o discurso universal. Discurso monótono, repetitivo, como a própria existência humana. Numa história assim determinada as posições rebeldes não têm como tornar-se 
revolucionárias.” Assim, como já mencionado, os Morlocks não tomam posição por si, eles se escondem e vivem nas sombras porque a realidade deles é assim mesmo e não há o que fazer para mudá-la. Esse sentimento de impotência para a mudança, que no fundo deve ser desejada por eles, essa impossibilidade da convivência, do ir e vir desperta neles o legítimo sentimento da raiva.

Freire (2000, p. 79) aponta que se a realidade fosse assim porque estivesse dito que assim teria de ser não haveria sequer por que ter raiva. Outro apontamento do autor que pode ser relacionado a raiva desses personagens está em sua obra Pedagogia da Autonomia (2015). É difícil, porque nem sempre temos o valor indispensável para não permitir que a raiva que podemos ter de alguém vire raivosidade que gera um pensar errado e falso. Nesse caso, podemos interpretar o pensar errado e falso com a visão e com o julgamento que eles fazem dos X-Men, assim como humanos julgam todos os mutantes de forma precipitada, formando assim uma rede de opressores - oprimidos. Para Freire (2005) não basta que opressores e oprimidos tenham consciência dessa relação, é necessário que ambos se entregam a uma prática libertadora para que essa relação de fato se acabe. Reconhecer-se no papel de opressor não é realmente solidarizar-se com o oprimido, não basta que os X Men se compadeçam pela situação dos Morlocks, as duas equipes deveriam se juntar em uma busca pela liberdade para que de fato se libertassem das relações opressoras. Nesse sentido, Freire (2015) acrescenta que: “Qualquer discriminação é imoral e lutar contra ela é um dever por mais que se reconheça a força dos condicionamentos a enfrentar. A boniteza de ser gente se acha, entre outras coisas, nessa possibilidade e nesse dever de brigar" (FREIRE, 2000, p. 59).

Assim, a guerra entre humanos e mutantes pode ser considerada mais grave, levando em consideração que no arco em questão haviam mutantes que caçavam seus semelhantes a mando do governo federal. Não se pode dizer aqui que os mutantes que caçavam seus pares estavam tentando lhes ensinar algo, pois, de acordo com Fiori (2005), os métodos de opressão não podem, contraditoriamente, servir à libertação do oprimido.

\section{Considerações finais}

A obra de Paulo Freire, na perspectiva da opressão, encontra aproximações com a história dos X-Men, especialmente na medida em que estes são os diferentes, os excluídos, os "feios". Quem são os X-Men da obra de Freire? Ele se refere aos que, por não compartilharem da mesma cultura, ou da mesma situação econômico-educacional, acabam sendo também excluídos. E ainda na perspectiva freiriana podemos perceber que os oprimidos, nesse caso retratados pelos Morlocks, não tomaram consciência de seu lugar no mundo. Foi aceitado tudo que lhes foi imposto sem questionar o porquê. Não houve nesse arco a libertação dos oprimidos e nem dos opressores. Não seriam também os próprios X-Men 
beneficiados por essa situação de opressão, uma vez que, eles estão privilegiados e nada fazem para mudar a situação de seus companheiros mutantes?

Por outro lado, Freire (2005) traz também o antídoto para a opressão, a qual ele sintetiza na ação dialógica, caracterizada, segundo ele, pela colaboração, união, organização e síntese cultural. Trata-se, mais do que qualquer coisa, da aceitação do diferente, seja pela pela sua cor, crenças, capacidades, cultura, ou saberes.

Isso significa que é na diversidade que nos completamos, que aprendemos e crescemos. Entretanto, se não nos abrirmos ao diálogo, à problematização e à escuta, essa ação dialógica não se concretizará.

\section{REFERÊNCIAS}

ARAÚJO FREIRE, Ana Maria. Paulo Freire: uma história de vida. 2. ed. rev. e atual. São Paulo: Paz e Terra, 2017.

BRASIL. Base Nacional Comum Curricular. Brasília: MEC, 2017. Disponível em: $<$ http://basenacionalcomum.mec.gov.br/abase/>

BRASIL. Parâmetros curriculares nacionais: introdução aos parâmetros curriculares nacionais. Brasília, DF: MEC, 1997. 126p. Disponível em: <http://portal.mec.gov.br/seb/arquivos/pdf/livro01.pdf>

CLAREMONT, Chris; JR, John Romita; GREEN, Dan. A Manhã Seguinte. Uncanny X Men 210. Outubro 1986.

CLAREMONT, Chris; JR, John Romita; BLEVINS, Bret. Massacre. Uncanny X Men 211. Novembro 1986.

CLAREMONT, Chris; GUICE, Jackson. Domingo Sangrento. New Mutants 46. Dezembro 1986.

CLAREMONT, Chris; LEONARDI, RICK. A Última Rodada. Uncanny X Men 212. Dezembro 1986.

CLAREMONT, Chris; DAVIS, Alan. Psylocke. Uncanny X Men 212. Janeiro 1987.

FIORI, Ernani Maria. Aprender a dizer sua palavra. In.: FREIRE, Paulo. Pedagogia do oprimido. São Paulo: Paz e Terra, 2005, p. 07-22.

FREIRE, Paulo. Pedagogia da indignação: cartas pedagógicas e outros escritos. São Paulo: Universidade Estadual Paulista, 2000. 134 p.

FREIRE, Paulo. Pedagogia do oprimido. 44 ed. São Paulo: Paz e Terra, 2005.

FREIRE, Paulo. Pedagogia da autonomia: saberes necessários à prática educativa. 50. ed. São Paulo: Paz e Terra, 2015.

IRWIN, William. Super-heróis e a filosofia: verdade, justiça e o caminho socrático. Tradução: Marcos Malvezzi Leal. São Paulo: Madras, 2005. 
RAMA, Angela. VERGUEIRO, Waldomiro. (orgs). Como usar as histórias em quadrinhos na sala de aula. 3ed. São Paulo: Contexto, 2006.

REBLIN, Iuri Andréas. Para o alto e avante: uma análise do universo criativo dos super- heróis. Porto Alegre: Asterisco. 2008.

SIMONSON, Louise; SHOEMAKER, Terry. Lobos em Pele de Cordeiro. X Factor 9. Outubro 1986.

SIMONSON, Louise; SIMONSON, Walter. Anjo Caído. X Factor 10. Novembro 1986.

SIMONSON, Walter; BUSCEMA, Sal. A Dádiva da Morte. The Mighty Thor 373. Dezembro 1986.

SIMONSON, Louise; BONGDANOVE, Jon. De Quem é o Poder?. Power Pack 27. Dezembro 1986.

SIMONSON, Walter; BUSCEMA, Sal. Chamas da Noite. The Mighty Thor 374. Dezembro 1986.

SIMONSON, Louise; SIMONSON, Walter; Redenção. X Factor 11. Dezembro 1986.

SINGER, Brian. (2000). X-Men: o filme. 20th Century Fox Film Corporation. 1 DVD (104 min.), color.

WELLS, H. G. A máquina do tempo. São Paulo, ALVES EDITORA S.A. 1981.

WESCHENFELDER, Gelson. Aristóteles e os super-heróis: a ética inserida nas histórias em quadrinhos. São Bernardo do Campo, SP: Garcia edizioni, 2014. 